\title{
Cochrane Collaboration's stand versus industry funding
}

New guidelines issued by the Cochrane Collaboration prohibit industry funding of Cochrane reviews. The guidelines followed revelations that a drug company with a stake in a Cochrane review provided funding for the review (BMF 2003;327:924-6).

Under the new rules, Cochrane review groups will not be allowed to receive any funding from "commercial sources with financial interests in the conclusions of Cochrane $\approx$ reviews." The collaboration reviews health interventions and disseminates the information worldwide.

Some Cochrane members opposed the restrictions, saying they would threaten the organization's financial viability. But Dr. James
Neilson, co-chair of the collaboration's steering group, said the decision reflected the "overwhelming agreement of the steering group and the members of the collaboration that there needs to be a clear separation between production of reviews and commercial sponsorship.

Neilson wasn't sure about the financial impact of the decision. "There are some entities that will find themselves in some difficulty, but that's why there is a transition period to allow them to seek alternate sources of funding."

Dr. Gordon Guyatt of McMaster University in Hamilton, Ont., said governmental agencies have not given the support the collaboration needs. "Look at the human genome project. What
Cochrane is doing is at least as important and yet it receives less than 1/1000th of the funding."

Health Canada has funded the Canadian Cochrane Centre previously, but spokesperson Paige Raymond Kovac "couldn't say what the future will hold."

The Canadian Institutes of Health Research currently fund the Centre; however, Sonja Corkrum, vice president of knowledge translation, said other models of research dissemination are competing for funds.

The new guidelines also establish a central fund that could accept industry funding and a "funding arbiter" position to manage potential conflict of interest cases. - Feanne Lenzer, Kingston, NY

\section{Medicolegal}

\section{Medicare on trial: Chaoulli and autism case}

Is health care a right? That question lies at the heart of 2 landmark cases heard by Supreme Court justices in early June. One case could open the way to 2-tier medicine, while the other, concerning payment for therapy for autistic children, could result in ô skyrocketing health care costs.

On June 8, Dr. Jacques Chaoulli and patient George Zeliotis asked Canada's highest court to overturn 2 earlier judgements by Quebec courts that upheld provincial laws limiting the use of private medical services or

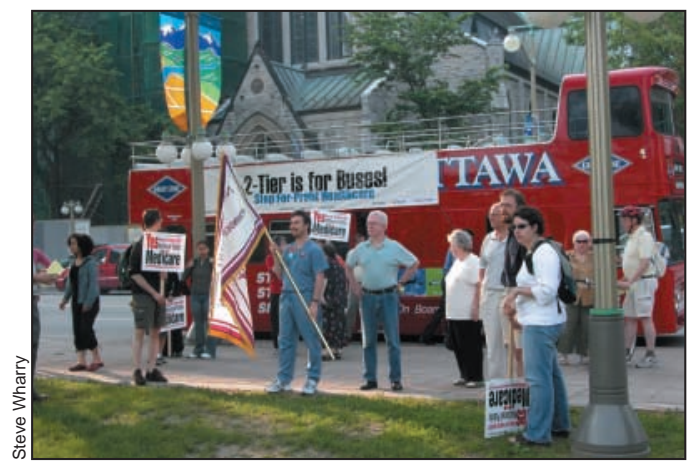

No to 2-tier: Protestors near the Supreme Court of Canada. medical insurance. They contend that their rights under the Canadian Charter of Rights and Freedoms were breached by these prohibitions (CMA7 2003;169 [2]:140). A ruling is expected in late fall or early winter.

Philippe Trudel, a lawyer for Zeliotis, said the justices must decide whether Canadians should be allowed to use their own money to buy care that the publicly funded system cannot provide and whether the state can prevent people from receiving the health care they need by buying it with their own money. He argued that Zeliotis' Charter rights were breached because of the pain he was forced to endure while awaiting a hip replacement, which resulted in dependency on pain medication.

\section{Autism case}

On June 9, another pivotal case involving payment for therapy for $4 \mathrm{BC}$ children with autism was heard by the same 7 Supreme Court justices. A ruling is not expected for months. The behav- ioural intervention treatment developed by Dr. Ivan Lovaas, which costs up to $\$ 60000$ a year, was originally deemed "experimental and not a medically necessary service" by the BC government. Several parents sued, and $\mathrm{BC}$ courts ruled the government had violated the Charter's equality guarantees for the disabled.

During the hearing, 7 provinces and the federal government warned that allowing judges to order costly treatment would destroy the ability of provinces to run their health care systems, since a victory for the parents could result in similar requests on behalf of other patients. "Governments will have to have unlimited budgets in order to respond to that constitutional imperative," said federal lawyer Graham Garton.

The children's lawyer argued that the therapy may allow them to lead meaningful, independent lives, instead of being institutionalized at a cost of $\$ 500000$ annually. - Barbara Sibbald, CMAJ, and Pat Sullivan, CMA 